\title{
Transitions to informal care in Great Britain during the 1990s
}

\section{Hirst}

\begin{abstract}
Objectives: To estimate annual changes and trends in the population of informal carers and to investigate transitions to caregiving by age, gender, locus of care, and level of involvement.

Design: Longitudinal analysis of data from the British household panel survey, 1991 to 1998, an annual prospective survey of a nationally representative sample of more than 5000 private households in England, Scotland, and Wales.

Subjects: Over 9000 adults over 16 years interviewed personally in successive waves of the survey, including around 1300 informal carers each year.

Results: One third of co-resident carers and $40 \%$ of extra-resident carers start caregiving each year and similar proportions cease to provide care. Five year period rates are at least $75 \%$ higher than the one year prevalence estimates. Almost everyone is involved in caregiving at one time or another and over half are likely to provide 20 hours or more care per week at some point in their lives. Recent trends indicate that more adults are becoming heavily involved in providing longer episodes of care. Although the onset of caregiving peaks in late middle and early older age, above average incidences span three decades or more of adult life. Age variations in the start of caring relationships are driven by the changing demands for care within and between generations over the life course. There is no firm evidence that carers increase their involvement in caring activities over the first three years of a caring episode.

Conclusions: The population of carers is constantly changing as some people stop providing care and others take on a caring role or vary their level of involvement. Policy measures responsive to the diversity of caring roles, and geared around key transitions, are likely to be most effective in supporting carers through changing circumstances. Recognition and support for carers who are heavily involved in caring activities from the outset should be a priority.
\end{abstract}

Correspondence to: $\operatorname{Dr} M$ A Hirst, Social Policy Research Unit, University of York, YO10 5DD, UK; spru@york.ac.uk Accepted for publication 15 November 2001

T he market value, or replacement cost, of unpaid care provided by family members and friends to ill and disabled adults in the United States was estimated to be \$196 billion in 1997.' The economic value of informal caregiving in Britain is reported to be around $£ 34$ billion per year, although the methodologies used to produce such estimates are contested. ${ }^{\text {la } 2}$ However, few would argue that state provision of care could ever replace the carers' role or that, without their contribution, community health and social care services could cope with the additional demands on their resources. On the contrary, supporting informal carers in their caring role is high on the public policy agendas of many developed countries.

With mounting concern about funding the long term care needs of older people, a determined shift from institutional arrangements to community and home based provision, and uncertainty about the impact of demographic and social change on the demand for and supply of family care, government policies towards carers and the people they care for are evolving rapidly. ${ }^{3}$ Central to policy thinking is the relation between informal care and formal provision, and how to strike an appropriate and sustainable balance between cash payments and support services for both care recipients and carers. Various approaches can be observed as each country evolves a particular mix of policy responses, including home care, day care and respite services, cash allowances for carers, direct payments to disabled and older people to enable them to purchase care, and the protection of carers' pension rights. ${ }^{4-6}$

In Britain, there are an estimated 5.7 million adult carers, or $13 \%$ of people aged 16 years or over. ${ }^{7}$ A great deal is known about their circumstances, who cares for whom, the types of help given, and the time spent on caring activities. ${ }^{78}$ Much is also known from qualitative studies about how and why people take on a caring role, the costs and opportunity costs involved, as well as the satisfactions and difficulties of caring. ${ }^{9-11}$ Most British studies are cross sectional in design, however, providing few insights into the dynamics of caregiving.

There is growing recognition of both the practical and theoretical importance of adopting temporal perspectives on caregiving, its antecedents and its longer term consequences. ${ }^{12}$ A dynamic perspective is required to understand the considerable changes that carers typically experience, and draws attention to the duration and cumulative impact of caregiving. ${ }^{13}$ Identifying stages in the evolution of caring responsibilities and activities enables services and practical support to be tailored to meet carers' changing needs and circumstances. ${ }^{14}{ }^{15} \mathrm{~A}$ dynamic perspective is also required for understanding how community care policies operate, and for evaluating the effectiveness of the support carers receive directly and from the services organised primarily around the cared-for person. ${ }^{16}$ Current policy and practice has fuelled an increasing focus on measuring the outcomes of health and social care over time, including the impact on carers. ${ }^{17}$ Establishing the temporal order of events is also crucial for understanding the relationships between the caring role and carers' health, employment and financial circumstances.

Research on the dynamics of caregiving in Britain is particularly relevant at the moment for monitoring the impact and reach of recent policy initiatives on informal carers. The national strategy for carers, announced in February 1999, emphasises the importance of providing information for carers, supporting carers in their caring activities, promoting their health and social wellbeing, and maintaining their other roles, including paid employment. ${ }^{18}$ A key element of the 
strategy is the provision of ring fenced grants for local authorities to develop the range and quality of services for giving carers a break from caring. Another important measure is the introduction of a second state pension for carers. In addition, new legislation has extended carers' rights to an assessment of their own needs and service support independently of the person they look after. ${ }^{19}$ Advice on quality standards and the practices needed to meet key outcomes for carers have also been widely circulated to service planners and managers for use in audit and performance management. ${ }^{20}{ }^{21}$ Particular attention has focused on developing carer support projects in doctors' surgeries and the potential benefits of closer collaboration between the health services and carers' organisations. ${ }^{22}{ }^{23}$ Questions remain, however, about the effectiveness of these measures, the adequacy of the resources available, and the implications of targeting heavily involved carers. $^{24}$

This paper summarises what is presently known about carer transitions in Britain, drawing on new evidence from a prospective, population based survey. It provides up to date estimates of transitions into and out of caring, compares rates of turnover between subgroups of carers, and investigates time trends in carer transitions. The approach is mainly descriptive, to provide a quantitative framework for understanding better the dynamics of caregiving. As well as examining the changing population of carers, this paper provides estimates of the extent of informal care over time, the likelihood of people taking on a caring role, and the timing of care episodes during the life course. The implications of the findings for policy development and service provision are considered in the final section.

\section{METHODS}

\section{The sample}

This paper is based on secondary analysis of the British household panel survey. The BHPS is an annual survey of a representative sample of more than 5000 private households in Great Britain (that is, England, Scotland, and Wales), yielding almost 10000 adult interviews each year. ${ }^{25}$ The panel was recruited in 1991 when information was gathered on all those living in private households at sample addresses selected according to a two stage clustered probability design and systematic sampling. ${ }^{26}$ In later waves, all people over 16 years at wave one are interviewed, plus their natural descendants on turning age 16, and other adult members of their current household. Because the sample is augmented in this way, it remains broadly representative of the British population throughout the 1990s.

\section{Definitions}

Respondents over 16 years are asked whether they provide informal care for someone who is sick, elderly, or disabled, whether inside or outside their own household. Caregiving is defined as looking after, giving special help, or providing some regular service that is not provided in the course of paid employment. Informal care provided by younger people is not included in the survey.

The term "co-resident" describes those who provide informal care for someone in the same household, and "extraresident" is used to denote caring for someone living elsewhere, in another private household or in a communal establishment. Co-resident caregiving often involves the more demanding forms of care, help with personal care (for example, bathing, dressing, or using the toilet) and mobility. By comparison, out of household caring relationships are generally less intensive, concentrating on the provision of practical help such as housework and shopping. ${ }^{8}$

Carers are also distinguished according to their level of involvement, focusing particularly on those providing at least 20 hours of informal care a week and those providing 50 hours or more per week. Carers devoting long hours to their caring activities are more likely to provide personal and physical assistance to someone who lives in the same household, with no assistance from other people. ${ }^{27}$ The 20 hour threshold is commonly adopted by local social services authorities to target those providing a substantial amount of care on a regular basis for the purposes of obtaining a needs assessment under the Carers Act. ${ }^{28}$ In the survey, interviewers record the hours that people devote to caregiving according to one of ten categories, ranging from less than five hours to 100 or more hours per week; these categories are combined for the summary distributions presented here using a schema developed by others. ${ }^{29}$ The average number of hours was computed from the midpoint values of the intervals used in the survey with 112 , or 16 per day, representing the open-ended interval "100 or more hours per week".

\section{Data analysis}

This paper is based on the first eight waves of the BHPS from 1991 to 1998. Individual respondents can be linked across successive waves to identify transitions into and out of informal care, although it is not possible to define with any precision the onset or end of a caring role, or the reasons involved. All that is certain is whether caregiving begins or ends between two successive waves; informal care that starts and ends between successive waves is missed altogether. The duration of care episodes can be inferred from the number of consecutive waves at which caregiving is reported. With eight interview waves and no information on when caring activities commenced, new (incident) care episodes up to six "years" long can be identified; in practice, small sample sizes limit analysis to episodes of shorter durations. The observation period is too narrow to estimate with confidence the typical duration of caring episodes for different groups of carers or caring relationships.

It is acknowledged that caring activity reported at two or more consecutive waves does not necessarily imply that caregiving has been continuous throughout the intervening period, that the level of involvement in caring activities has been constant, or that the same person has been cared for. Further compromises are required. Within households, individual caring relationships can be traced across successive waves because both carer and care recipient form part of the enumerated sample, but extra-resident care recipients, of whom no more than two are identified, are known only by their relationship to the carer. Out of household care for a "parent or parent in law", one of the survey categories, could cover four different people, more if step or adoptive relationships are included. Moreover, it is not possible to discover whether spells of co-resident care were preceded or followed by the provision of extra-resident care for the same people. In this analysis, therefore, transitions into and out of informal care are defined not by the start or end of caring relationships, but by whether or not individuals provide informal care across successive interview waves.

Transitions to informal care are repeatable events, with some people providing care intermittently or occasionally, sometimes for the same person. It was decided to include all such events, treating each transition into informal care for each person as a separate event; these events were then pooled over all people.

The BHPS data can be weighted to take account of sample attrition and those people who refused an interview, were interviewed by proxy, or were unable to be interviewed. Weighted data give marginally higher incidence rates of informal care, though differences between the weighted and unweighted estimates are not statistically significant. There is no consensus on the use of sample weights, and it was decided to report the more conservative findings from the unweighted data. Analyses were conducted separately for male and female respondents because their circumstances around the transition to informal care differ widely. 
Table 1 Characteristics of adult informal carers at the start of caregiving by gender and locus of care (percentage)

\begin{tabular}{|c|c|c|c|c|}
\hline & \multicolumn{2}{|c|}{ Extra-resident carers } & \multicolumn{2}{|c|}{ Co-resident carers } \\
\hline & Women & Men & Women & Men \\
\hline \multicolumn{5}{|l|}{ Age group (y) } \\
\hline 16 to 24 & 7 & 9 & 9 & 9 \\
\hline 25 to 34 & 14 & 12 & 15 & 11 \\
\hline 35 to 44 & 20 & 19 & 18 & 17 \\
\hline 45 to 54 & 24 & 22 & 15 & 17 \\
\hline 55 to 64 & 16 & 18 & 16 & 18 \\
\hline 65 to 74 & 13 & 14 & 16 & 15 \\
\hline 75 or over & 6 & 6 & 11 & 13 \\
\hline \multicolumn{5}{|l|}{ Hours caring per week } \\
\hline Less than 5 hours & 56 & 63 & 21 & 26 \\
\hline 5 to 9 hours & 23 & 19 & 16 & 17 \\
\hline 10 to 19 hours & 12 & 11 & 20 & 21 \\
\hline 20 to 49 hours & 6 & 5 & 19 & 21 \\
\hline 50 hours or more & 2 & 3 & 24 & 15 \\
\hline Base: number of carers & 1569 & 1052 & 457 & 402 \\
\hline \multicolumn{5}{|l|}{ Relationship of care recipient to carer } \\
\hline Spouse/partner & - & - & 54 & 56 \\
\hline Parent/in law & 40 & 42 & 17 & 22 \\
\hline Son/daughter & & & 21 & 18 \\
\hline Brother/sister & 20 & 20 & 2 & 3 \\
\hline Other relative & & & 3 & 2 \\
\hline Client of voluntary organisation & 8 & 6 & - & - \\
\hline Friend/neighbour & 31 & 30 & & \\
\hline Other & 2 & 2 & 2 & 0 \\
\hline Base: number of caring relationships & 1863 & 1275 & 465 & 409 \\
\hline
\end{tabular}

Respondents who start, cease or continue providing informal care were identified from cross tabulations across successive waves using SPSS version 10. Prevalences and incidences of informal care, based on person years of observation, and cumulative rates and risks for each year of adult life were estimated according to commonly used techniques. ${ }^{30}$ The paired $t$ test and the $\chi^{2}$ test for symmetry ${ }^{31}$ were used to assess changes between successive interviews in the amounts of time that people devoted to their caring activities. Statistical significance was decided according to the five per cent level $(\mathrm{p}<0.05)$ and, where appropriate, 95\% confidence intervals (CI) were estimated to indicate the range that is most likely to include the findings that would be obtained if the total population were studied. ${ }^{32}$

\section{RESULTS}

Table 1 summarises key characteristics of the sample of "new" carers, that is, those people who said they were providing informal care at each wave, but not at the preceding one. The data illustrate well established patterns: a predominance of women especially among extra-resident carers, most carers in middle to early old age, the heavier involvement of those providing informal care inside their own homes, the importance of spouse care, and the extent of inter-generational caregiving both within and between households. ${ }^{72733}$ Caregiving within households often demands higher levels of involvement, whereas out of household care is more widespread, and a sizeable minority of extra-resident carers look after more than one person. There is no difference in the average age at which women and men take on a caring role (around 49 years for extra-resident carers and 51 years for co-resident carers). Women are more likely to look after a son or daughter while men are more likely to provide co-resident care for a parent or parent in law. However, women are more heavily involved than men in providing informal care inside their own household. Although women predominate in all extra-resident caring relationships, similar proportions of women and men carers are involved in each type of relationship described here.

\section{The changing population of carers}

Annual estimates of changes in carer status indicate similar rates of entry to and exit from caregiving (table 2). This is the case within both the female and male populations irrespective of locus of care or level of involvement in caring activities.

The findings also draw attention to extremely high rates of turnover in the carer population. Carer turnover is represented by the number of people who start caregiving during a year as a proportion of all those providing care at the end of that year, and by the number ceasing care as a proportion of all those providing care at the start of a year. Thus $41 \%$ of extra-resident carers, women and men combined, had started caregiving in the previous year while a similar proportion $(42 \%)$ ceased caregiving in the following 12 months. Turnover is lower among co-resident carers (32\% start and 30\% cease) but somewhat higher in the case of those providing 20 hours or more care per week ( $44 \%$ start and $41 \%$ cease). People moving across the 20 hour threshold are almost equally divided between carers varying their involvement in caring activities (47\%) and those moving into or out of a caring role $(52 \%)$. By comparison, those crossing the $\mathbf{5 0}$ hour threshold are more likely to be increasing or decreasing their involvement (61\%) than starting or ceasing to provide informal care (39\%). Although more women than men take on a caring role, there are no gender differences in turnover rates except for out of household care, where men start and cease providing care more frequently than women $(62 \%$ and $57 \%$ respectively; $\mathrm{p}<0.001$ )

These estimates of annual change can be applied to typical populations at an area or organisational level to provide better indications than are currently available of the number of adult carers over time. For example, health and social care professionals in a typical local authority area with 250000 adults might expect to provide the information and support needs of over 3000 new, heavily involved carers (those providing at least 20 hours care per week) every year, that is 12 per working day on average. A comparable figure for a typical general medical practice with three family doctors and 4500 adult patients would be around 60 per year. 
Table 2 Annual prevalence of carer transitions in the adult population by gender, locus of care, and number of hours spent caring per week

\begin{tabular}{|c|c|c|c|c|}
\hline \multirow[b]{2}{*}{ Annual transitions } & \multicolumn{2}{|c|}{ Women } & \multicolumn{2}{|l|}{ Men } \\
\hline & \multicolumn{2}{|c|}{ Rate per $1000(95 \% \mathrm{Cl})$} & \multicolumn{2}{|c|}{ Rate per $1000(95 \% \mathrm{Cl})$} \\
\hline \multicolumn{5}{|l|}{ Extra-resident carers } \\
\hline Starting & 49.8 & (47.4 to 52.2 ) & 39.7 & (37.3 to 42.0$)$ \\
\hline Continuing & 76.3 & (73.4 to 79.3$)$ & 50.0 & (47.4 to 52.6$)$ \\
\hline Ceasing & 52.4 & (49.9 to 54.8$)$ & 40.6 & (38.2 to 43.0 ) \\
\hline \multicolumn{5}{|l|}{ Co-resident carers } \\
\hline Starting & 14.7 & (13.4 to 16.1$)$ & 15.3 & (13.8 to 16.8$)$ \\
\hline Continuing & 32.6 & $(30.6$ to 34.6$)$ & 30.3 & (28.2 to 32.3$)$ \\
\hline Ceasing & 13.8 & (12.5 to 15.1$)$ & 13.2 & (11.8 to 14.6$)$ \\
\hline \multicolumn{5}{|c|}{20 hours or more per week } \\
\hline Starting & 15.2 & $(13.9$ to 16.6$)$ & 10.9 & $(9.7$ to 12.2$)$ \\
\hline Continuing & 19.4 & (17.8 to 20.9 ) & 13.8 & (12.4 to 15.3 ) \\
\hline Ceasing & 13.9 & (12.6 to 15.2$)$ & 9.3 & $(8.1$ to 10.5$)$ \\
\hline \multicolumn{5}{|c|}{50 hours or more per week } \\
\hline Starting & 8.5 & $(7.5$ to 9.6$)$ & 6.1 & (5.1 to 7.0$)$ \\
\hline Continuing & 8.7 & (7.7 to 9.8$)$ & 6.4 & (5.4 to 7.3$)$ \\
\hline Ceasing & 7.8 & (6.8 to 8.7$)$ & 5.0 & (4.1 to 5.9 ) \\
\hline
\end{tabular}

Table 3 Prevalence of informal care among adults in Great Britain by gender, locus of care, and number of hours spent caring per week

\begin{tabular}{|c|c|c|c|c|}
\hline \multirow[b]{2}{*}{ Time period } & \multicolumn{2}{|l|}{ Women } & \multicolumn{2}{|l|}{ Men } \\
\hline & $\begin{array}{l}\text { Rate per } \\
1000\end{array}$ & $(95 \% \mathrm{Cl})$ & $\begin{array}{l}\text { Rate per } \\
1000\end{array}$ & $(95 \% \mathrm{Cl})$ \\
\hline \multicolumn{5}{|c|}{ Extra-resident carers } \\
\hline Point & 123.6 & (120.3 to 126.8 ) & 86.0 & (83.0 to 88.9 ) \\
\hline One year & 176.4 & (172.4 to 180.4 ) & 127.2 & (123.4 to 131.0 ) \\
\hline Three year & 253.3 & (247.9 to 258.7 ) & 188.4 & (183.1 to 193.6$)$ \\
\hline Five year & 313.2 & (305.9 to 320.6 ) & 237.6 & (230.3 to 244.9 ) \\
\hline Seven year & 363.0 & (350.0 to 376.1$)$ & 276.8 & (263.6 to 289.9 ) \\
\hline \multicolumn{5}{|c|}{ Co-resident carers } \\
\hline Point & 45.8 & (43.7 to 47.8 ) & 44.0 & (41.8 to 46.2 ) \\
\hline One year & 62.0 & (59.4 to 64.5$)$ & 60.3 & (57.6 to 63.0$)$ \\
\hline Three year & 86.7 & (83.2 to 90.2 ) & 86.2 & (82.4 to 90.0 ) \\
\hline Five year & 109.6 & (104.5 to 114.6 ) & 108.0 & $(102.6$ to 113.4$)$ \\
\hline Seven year & 131.8 & (122.5 to 141.2 ) & 131.2 & (121.2 to 141.3$)$ \\
\hline \multicolumn{5}{|c|}{20 hours+ carers } \\
\hline Point & 34.0 & (32.2 to 35.8 ) & 24.2 & (22.6 to 25.9 ) \\
\hline One year & 50.2 & $(47.9$ to 52.6$)$ & 35.7 & (33.6 to 37.9 ) \\
\hline Three year & 74.9 & (71.6 to 78.2$)$ & 55.2 & (52.1 to 58.3 ) \\
\hline Five year & 96.9 & (92.1 to 101.6$)$ & 70.9 & $(66.4$ to 75.3$)$ \\
\hline Seven year & 120.8 & (111.6 to 129.9 ) & 87.0 & (78.5 to 95.4 ) \\
\hline \multicolumn{5}{|c|}{50 hours+ carers } \\
\hline Point & 17.0 & (15.7 to 18.3 ) & 12.4 & (11.2 to 13.6 ) \\
\hline One year & 25.8 & (24.1 to 27.5 ) & 18.8 & (17.2 to 20.3 ) \\
\hline Three year & 39.6 & (37.2 to 42.1 ) & 28.7 & (26.4 to 30.9 ) \\
\hline Five year & 51.7 & (48.1 to 55.3 ) & 37.1 & (33.8 to 40.4 ) \\
\hline Seven year & 64.8 & (57.9 to 71.8 ) & 46.2 & (39.9 to 52.6$)$ \\
\hline
\end{tabular}

\section{Prevalence of informal care}

The greater the turnover of carers, the higher the number of people who are involved in caregiving over time. Table 3 shows that one year prevalence rates for women and men alike are between one third and one half as much again as the point estimates. Five year period rates for both extra-resident and co-resident caregiving are $75 \%$ or more higher than the one year rates. The differences are greater for heavily involved carers: almost twice as many people identify themselves as heavy carers during a five year period as in a one year period. The rates of increase in the proportion of carers as the observation period widens are similar for women and men alike.

(The one year prevalence rates shown in table 3 exceed slightly the sum of the rates for those starting, continuing and ceasing care shown in table 2, because the latter estimates require stricter treatment of missing data.)

\section{Recent trends}

The transition rates presented above are aggregate estimates across the study period as a whole. During the 1990s, however, the proportions of both women and men who became heavily involved in providing informal care increased. ${ }^{34}$ The number of carers providing 20 hours or more care per week across successive waves increased by around 7\% a year (women: $\mathrm{OR}=1.07,95 \%$ CI 1.02 to 1.11 ; men: $1.08,1.03$ to 1.14 ). This trend towards more intensive caregiving is attributable in part to a declining incidence and duration of the less demanding types of care for friends and neighbours, and for clients of voluntary organisations. At the same time, there was an increase in the more intensive caring relationships within households associated with spouse care in older age and, to a lesser extent, the provision of care for a child or elderly parent. Although extra-resident care declined overall (women: 0.96, 0.95 to 


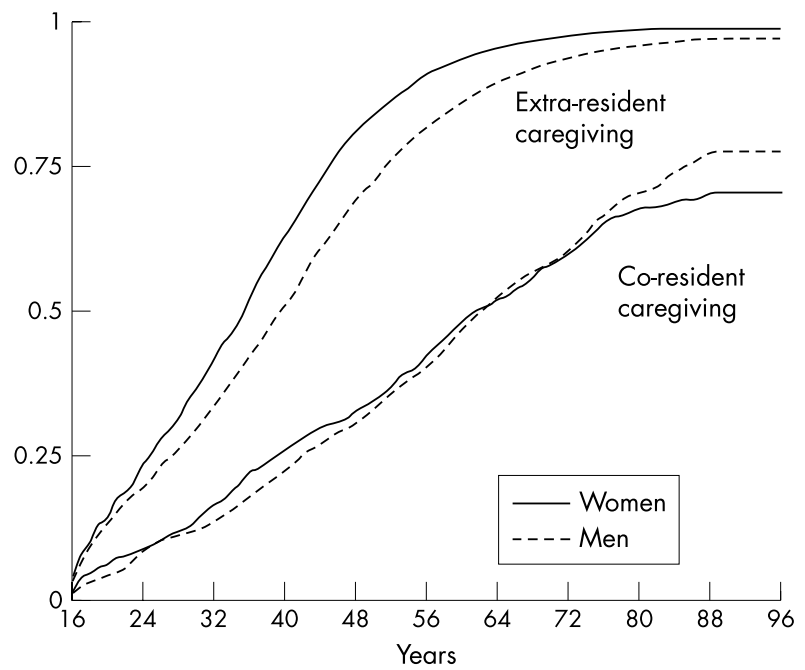

Figure 1 Cumulative probability of informal care by age, gender, and locus of care.

0.98; men: $0.98,0.96$ to 0.99 ), out of household care for elderly parents provided by daughters and daughters in law increased over the study period.

These trends reflect recent changes in society including: rising numbers of frail older people, increased chances of living with a spouse in old age, higher rates of home ownership among more recent cohorts of older people, and continuing improvements in the life expectancy of severely disabled children. $^{34}$

\section{Cumulative probability of informal care}

Figures 1 and 2 chart the cumulative risks, or probabilities, of becoming an informal carer for each year of adult life by locus of care and involvement in caregiving. They show how the probability of taking on a caring role adds up with age, assuming that people are not subject to competing risks: admission to institutional care for example, or death. ${ }^{30}$ Figure l shows that virtually everyone is likely to provide informal care outside their own household at some stage during a full life span, while almost six out of ten people are likely to have looked after someone in the same household by the time they reach their 70th year. The comparable probabilities of providing 20 hours or more care a week, or at least 50 hours a week, are somewhat lower: around half and one third respectively.

As expected, gender differences in net risk over the life span are most striking among the more heavily involved carers, highlighting the provision of physical and personal care by women for disabled children or elderly parents. If 100 women were to reach their 65 th birthday, for example, $56 \%$ of them would have provided at least one episode of 20 hours or more informal care a week and 34\% at least 50 hours a week; comparable proportions for men are $40 \%$ and $25 \%$ respectively. Women in their late 30 s to early 50 s are also more likely than men to provide care between households. During these years, men lag 10 percentage points behind women in the cumulative risk of providing out of household care. Gender differences in the risk of becoming a co-resident carer are negligible, except beyond the age of 75 when men are more likely than women to start looking after someone inside their household. In this age group, more men than women still have a spouse who might require informal care..$^{35}$

\section{Age specific incidence}

Figures 3 and 4 show more precisely when people are likely to take on a caring role during their life span. The incidence of extra-resident caregiving increases with age, peaks around ages 55 to 64 years, and then declines through the older age

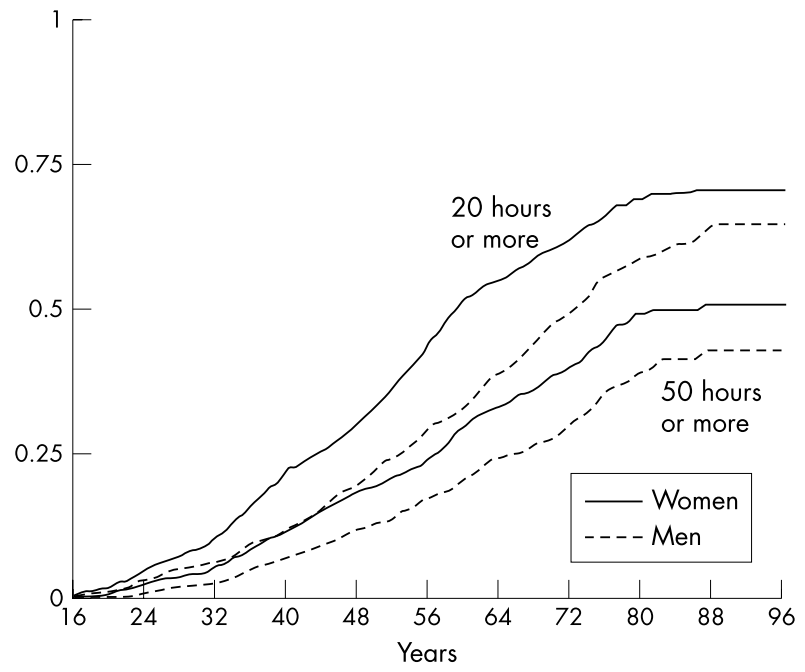

Figure 2 Cumulative probability of informal care by age, gender, and numbers of hours spent caring per week.

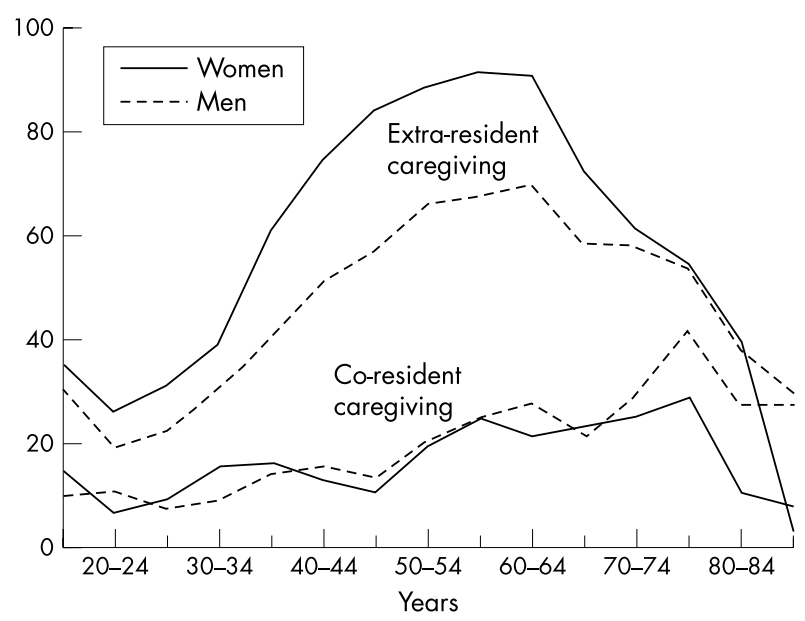

Figure 3 Annual incidence of informal care by age, gender, and locus of care (rate per 1000).

groups (fig 3). Women are more likely than men to become extra-resident carers across almost the entire age range. By comparison, the incidence of co-resident caregiving fluctuates somewhat, but generally increases with age until around 75 years. A similar profile is evident for the start of heavy caregiving with more extreme fluctuations in incidence rates for women: around one peak during the late 50s and another in the late 70 s (fig 4).

Despite these variations by age, above average incidence rates span a wide band of consecutive age groups. People face an increased likelihood of taking on a caring role over three decades or more from their mid-40s onwards, earlier in the case of out of household care. Caregiving therefore intersects with different stages of the life cycle and, as a consequence, carers' characteristics, family structures, and household circumstances are extremely diverse..$^{72736}$

\section{Caring relationships}

Most caregiving is based on close personal relationships within and between generations. How these converge over the life course largely determines the incidence, timing, and duration of caring episodes. Although the likelihood of starting to look after a friend or neighbour increases with age, the age profile of new extra-resident carers is dominated by the onset of caring for parents and parents in law. This increases rapidly, 


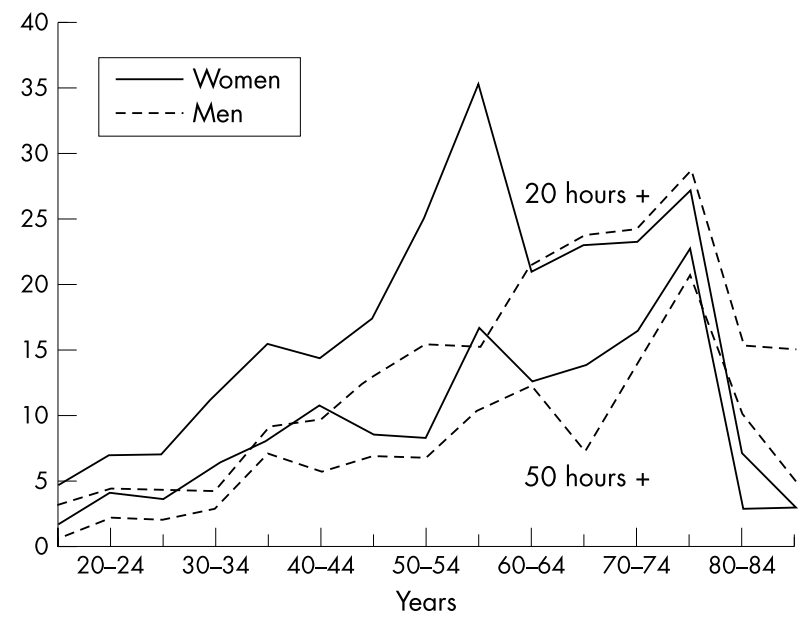

Figure 4 Annual incidence of informal care by age, gender, and number of hours spent caring per week (rate per 1000).

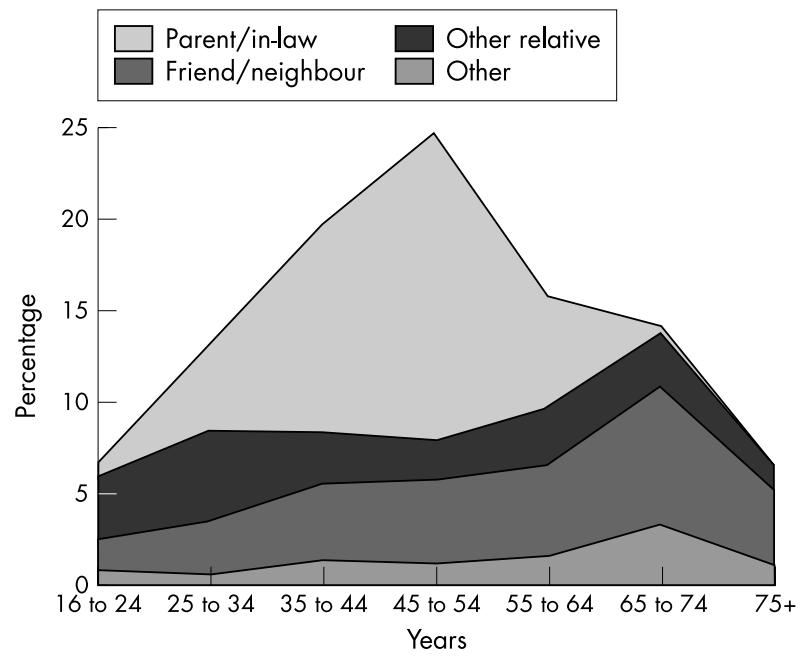

Figure 5 Women's ages at the start of extra-resident caregiving by care recipient's relationship to their carer (base: all caring relationships).

peaks around age 50 and declines as quickly (fig 5 and 6). By comparison, the age profile of co-resident carers is shaped by the interplay between providing informal care for younger and older generations, as well as spouse care (fig 7 and 8). Not surprisingly, caring for a sick or disabled son or daughter starts predominantly during the child rearing years, especially when parents are in their 30s and early 40s; a very small proportion of parents start looking after an adult child in later years. Sons and daughters taking on the care of a parent in the same household span a much wider age range; most start to do so in their mid-30s to mid-50s. The likelihood of providing informal care for a spouse or partner increases with age, and most caring relationships that start after age 55 are between spouses.

Table 4 shows further that differences in the ages of women and men on entering caring relationships are small, although the average misrepresents the bimodal distribution of women's ages at the start of co-resident care for a parent or parent in law shown in figure 7. Caring for parents or parents in law is the only relationship identified in both spheres of caregiving, and table 4 shows that such care starts at a much earlier age when it is provided within the same household as the carer, than when it is provided between the carer's and the care recipient's household. Co-resident care for parents is mostly provided by single or never married daughters and sons who have yet to leave, or may have returned to, the

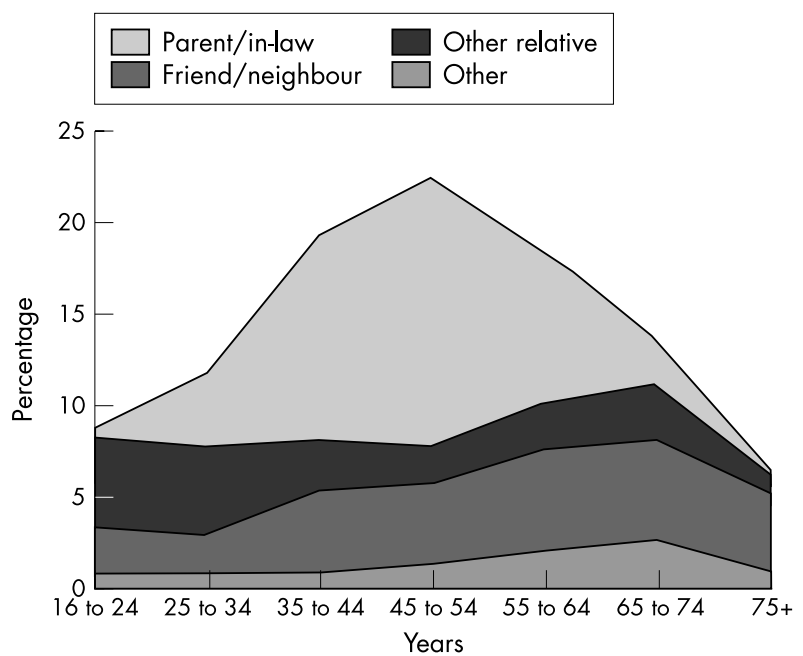

Figure 6 Men's ages at the start of extra-resident caregiving by care recipient's relationship to their carer (base: all caring relationships).

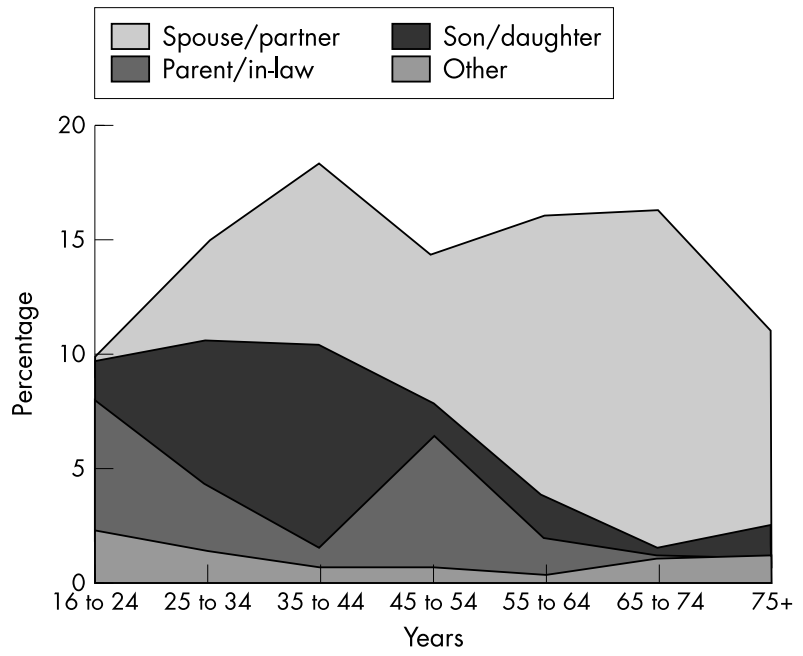

Figure 7 Women's ages at the start of co-resident caregiving by care recipient's relationship to their carer (base: all caring relationships).

parental home. Divorced or separated daughters also comprise a sizeable minority of these carers. By comparison, extraresident care of parents and parents in law is predominantly provided by adult children who are living as married and often have family commitments of their own. ${ }^{33}$

\section{Changes in time spent caring}

It was hypothesised during this study that carers would devote an increasing amount of time to their caring activities especially where the care recipients' medical conditions worsen, or they become more frail or dependent on others. The first three years of a caring episode is the maximum spell that sample numbers would allow to investigate this hypothesis. It was also necessary to focus on those carers with one care recipient only to remove changes in the amount of time devoted to caregiving that might arise from changes in the number of care recipients over time. However, it was beyond the scope of this analysis to distinguish between different types of caring relationship.

When the time devoted to informal care by those in their second or third consecutive year of caregiving is paired with their involvement in earlier years of the care episode, there is no firm evidence that people increased their involvement in 


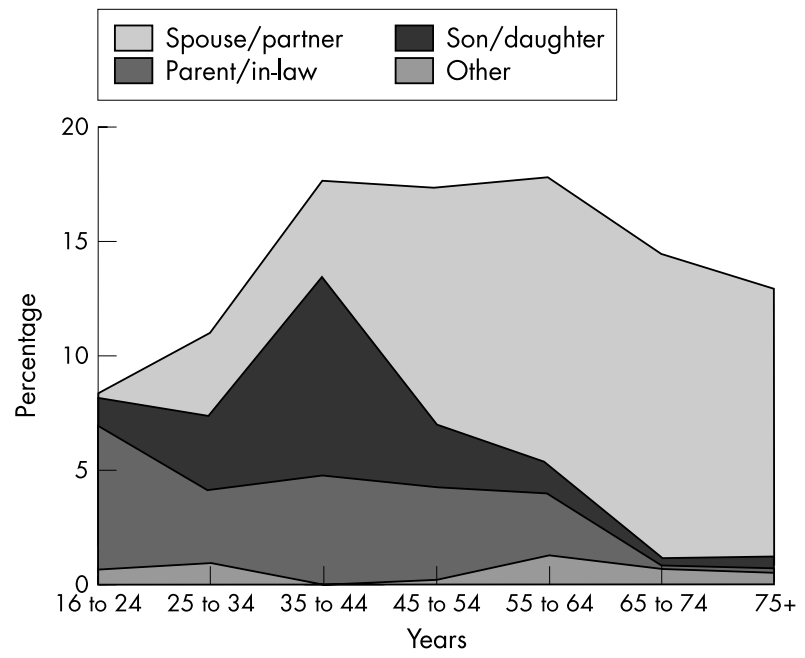

Figure 8 Men's ages at the start of co-resident caregiving by care recipient's relationship to their carer (base: all caring relationships).

caring activities over time ( $p>0.05$ between first and second years, and between second and third years, by gender and locus of care). It seems that people who continued providing informal care beyond their first reported caring relationship were heavily involved in caring activities from the outset; those providing informal care at one wave only devoted fewer hours on average to their caring activities. This suggests that there are substantive differences in the intensity and scope of caregiving between short, transitory spells and longer episodes. Data on caring activities, to explore the association between duration and patterns of care, are not collected in the BHPS however.

\section{DISCUSSION}

Longitudinal studies of informal care in several countries have drawn attention to the considerable changes in the population of carers over time, although international comparisons are hampered by differences in the definition of caregiving and how it is measured..$^{37}{ }^{38}$ In Britain, the population of carers is constantly changing as people stop providing care and others take on a caring role or vary their level of involvement. A substantial minority start and cease providing informal care each year. Recent trends point to a decline in the less demanding caring activities between households, and an increase in the more intensive forms of care for parents, elderly spouses, and disabled or technology dependent children.

It is no longer possible to regard informal carers as a discrete fixed group, nor to draw hard and fast distinctions between them and the remainder of the population. Most

\section{Key points}

- Between $30 \%$ to $40 \%$ of informal carers in Britain stop providing care and a similar proportion take on a caring role each year.

- Two thirds of women and over half of men will provide 20 hours or more informal care per week sometime in their lives before age 75 .

- Although the onset of caregiving peaks in late middle and early older age, above average incidences span 30 years or more of adult life.

- Age variations in the start of caring relationships are driven by changing demands for care within and between generations over the life course.

- Heavy carers are likely to be heavily involved from the outset of caregiving and for longer periods than those providing fewer hours of care a week.

people are involved in caregiving at one time or another, albeit for many this will be an activity more accurately described as informal helping or neighbouring. None the less, over half the adult population are likely to be heavily involved in providing informal care at some point in their lives. Although the onset of caregiving peaks in late middle and early older age, above average incidence rates span three decades or more of adult life. Age variations in the start of caring relationships are driven by the changing demands for care within and between generations over the life course. Gender differences draw attention to the increased likelihood of women providing informal care and their greater involvement, but there is no difference in rates of turnover between women and men who are heavily involved in looking after someone inside their own household.

High rates of carer turnover have important financial and administrative implications for developing services to support carers in their caring role. Underestimates of turnover would result in the needs of many carers, and the people they care for, not coming to the attention of service providers, and a risk that formal support is slow, inflexible, and therefore inappropriate. On the other hand, overestimates of turnover would inflate the number of carers over time and could lead to wasteful care management resources and higher unit costs. Across service planning, commissioning and budgeting cycles, there will be many more carers than have been shown in cross sectional estimates of the carer population. If provision for carers is developed on the basis of such estimates, resources will be stretched and support services will be inadequate. The findings also indicate that more carers became heavily involved in providing longer episodes of care during the 1990s. If this trend continues beyond the study period, increasing resources will be required to assess their needs and to support them in their caring activities.

Table 4 Adult carers' ages at the onset of caregiving by gender, relationship of care recipient, and locus of care (years)

\begin{tabular}{|c|c|c|c|c|c|c|}
\hline \multirow{2}{*}{$\begin{array}{l}\text { Relationship of care recipient } \\
\text { to the carer }\end{array}$} & \multicolumn{3}{|c|}{ Women } & \multicolumn{3}{|l|}{ Men } \\
\hline & Mean & SD & $(95 \% \mathrm{Cl})$ & Mean & SD & $(95 \% \mathrm{Cl})$ \\
\hline \multicolumn{7}{|l|}{ Extra-resident carer } \\
\hline Parent/in law & 45.4 & 9.4 & (44.7 to 46.1 ) & 48.1 & 10.9 & (47.2 to 49.1 ) \\
\hline Other relative & 44.3 & 19.1 & (42.3 to 46.2 ) & 42.0 & 19.2 & (40.0 to 44.4 ) \\
\hline Friend/neighbour & 55.3 & 17.7 & (53.8 to 56.8$)$ & 54.0 & 18.4 & (52.2 to 55.9 ) \\
\hline Other & 55.0 & 18.1 & (52.3 to 57.7$)$ & 53.9 & 18.4 & (50.4 to 57.4 ) \\
\hline \multicolumn{7}{|l|}{ Co-resident carer } \\
\hline Spouse/partner & 59.1 & 15.1 & (57.2 to 61.0$)$ & 60.9 & 14.8 & (58.9 to 62.8 ) \\
\hline Son/daughter & 39.6 & 14.3 & (36.8 to 42.5 ) & 40.5 & 11.7 & (37.7 to 43.2 ) \\
\hline Parent/in law & 37.1 & 15.6 & (33.6 to 40.5 ) & 38.3 & 15.0 & (35.1 to 41.5 ) \\
\hline Other & 42.3 & 23.4 & (33.9 to 50.8 ) & 45.3 & 22.6 & (34.7 to 55.9 ) \\
\hline
\end{tabular}


Carer turnover also has implications for policies designed to overcome barriers to combining paid work with caregiving, or to enable people to move more easily between employment and benefit receipt, and to return to paid work after caregiving ends. The findings show that almost half the adult population take on a heavy caring role before reaching pension age. Moreover, the peak time for the onset of caregiving coincides with the pre-retirement years, when financial provision for old age is consolidated. Enabling carers to maintain their attachment to the labour market could bring immediate and longer term benefits to the working population, more so as women's employment continues to expand and their incomes increasingly sustain household finances. ${ }^{6}$ Where carers have to relinquish paid work, opportunities to develop human capital during a caring episode would help maintain their employability. For those who want to work, family friendly employment practices, like job share and flexible working time, would help carers to achieve a better balance between the demands of paid work and home life. Specific leave arrangements including time off in emergencies, access to a telephone, and counselling will be especially helpful to those struggling to sustain their caring roles. Despite government encouragement, however, the adoption of such measures is extremely patchy, while welfare to work schemes often give insufficient attention to carers' commitment to their caring roles and the additional costs to them of caring. ${ }^{39}{ }^{40}$ There is no firm evidence, therefore, on the effectiveness of these measures for sustaining carers' employment and reducing the risk of poverty and social exclusion. ${ }^{41}$

Underestimating the rate of transition into caregiving may explain in part why informal carers often feel taken for granted or ignored, despite their increasing priority in policy and service development. ${ }^{142}$ Informing carers of social security benefits, and their right to an assessment for service support, is not routine practice, while the quality, type, and availability of service support varies considerably. ${ }^{43-45}$ As a consequence, many carers may have been caring for some time before getting the support they need, or may never receive it.

It can be difficult, however, to pinpoint the start of caregiving because many people feel they are fulfilling family obligations and regard caregiving as part of their normal, everyday activities. ${ }^{11}$ We know surprisingly little about how people come to define themselves as carers, and what prompts them to seek help and access services. Identifying transitions into informal care therefore represents a challenge to professionals and service providers who are aiming to support informal carers, target those with greatest needs, and provide timely support. Indeed, the time is ripe for a trial of the methods currently used to identify and follow up carers. Recognition and support for carers who are heavily involved in caring activities from the outset should be a priority. In the meantime, increased awareness of carers' roles and responsibilities through the media and other public information, and wider promotion of their employment, health and social needs would, on the evidence presented here, benefit a large section of the population over time.

The pattern of transitions to informal care across different phases of the life course draws attention to the diversity of carers' circumstances and how these interact with caring relationships. Not surprisingly, the acceptability and effectiveness of carer policies and service provision varies considerably between different groups of carers. ${ }^{16}$ Policies towards carers have to be both flexible and comprehensive if they are to respond fully to carers' heterogeneous needs and changing circumstances. The involvement of multiple service providers that this implies, including not for profit and carers' organisations, requires effective coordination and a shared commitment to supporting carers. A further implication is that service providers are likely to be most effective in meeting carers' needs when they provide high quality advice and information on the complete range of benefits and services for carers, sign- post or refer carers to local agencies and, where appropriate, act as brokers of services. Well informed carers are likely to contact the most relevant professional or service provider and make fewer inappropriate demands. ${ }^{21}$

The timing of interventions around transition points, such as hospital discharge ${ }^{46}$ or the move from children's services to adult provision ${ }^{47}$ is likely to be important for ensuring positive outcomes for both carers and care recipients, and for preventing or alleviating adverse consequences. In addition, checks on benefits entitlement, support needs, work related measures and health, whenever a suitable opportunity arises, or at regular intervals, would help to sustain those providing extended spells of informal care. The end of a protracted spell of heavy care can be particularly difficult for carers, especially when the cared for person dies or enters institutional care. ${ }^{48} 49$ The circumstances of former carers also highlight the persistence of adverse health, social and financial consequences beyond caregiving, and a need to consider continuing support in the post-care period. ${ }^{50}{ }^{51}$ Change and transition in the caring role therefore point to areas where service performance assessment and audit could be usefully focused.

This study of carer transitions is necessarily limited by the data available in the BHPS and the assumptions made about changes between successive interview waves. The dynamics of caregiving undoubtedly reflect the dynamics of impairment and disability, and the changing needs of the cared for person, but that can form only part of the explanation. ${ }^{52} 53$ Understanding the decision to care and carers' willingness to continue providing care, as well as considering their changing needs and circumstances, and aspirations for the future, are also required..$^{11-13}{ }^{15}$ To incorporate the time dimension into an evaluation of informal care requires appropriate measures of the caring experience, and detailed sequence analysis to describe and interpret caregiving trajectories. A particular challenge is to construct typologies of caring episodes, for different groups of carers, in terms of the incidence, timing, duration and intensity of care. Policies that distinguish between such trajectories, and are geared around key transitions or turning points, are likely to be more effective than those that fail to take account of the time dimension in caring relationships. ${ }^{54}$

\section{ACKNOWLEDGEMENTS}

Data from the British household panel survey were made available through the Data Archive in accordance with current ethical guidelines and data protection regulations. The data were originally collected by the ESRC Research Centre on Micro-Social Change at the University of Essex. Neither the original collectors of the data nor the Archive bear any responsibility for the analyses or interpretations reported here. The views expressed are those of the author and are not necessarily shared by any individual, government department or agency.

Funding: the research on which this paper is based was funded by the UK Department of Health as part of its Outcomes of Social Care for Adults research programme.

\section{REFERENCES}

1 Arno P, Levine $C$, Memmott $M$. The economic value of caregiving Health Aff (Millwood) 1999; 18:182-8.

la Nuttall S, Blackwood R, Bussell B, et al. Financing long-term care in Great Britain. Journal of the Institute of Actuaries 1994;121:1-68.

2 Smith K, Wright K. Informal care and economic appraisal: a discussion of possible methodological approaches. Health Econ 1994;3:137-48.

3 Pickard L, Wittenberg R, Comas-Herrera, et al. Relying on informal care in the new century? Informal care for elderly people in England to 2031. Ageing Society 2000;20:745-72.

4 Schunk $M$. Responses to the care dilemma: a comparison of informal care policies. In: Developments and trends in social security 1996-1998. Geneva: International Social Security Association 26th General Assembly, Marrakech, 25-31 October 1998.

5 Glendinning C, Mclaughlin E. Paying for care: lessons from Europe. Social Security Advisory Committee, Research Paper 5, London: HMSO, 1993. 
6 Salvage A. Who will care? Future prospects for family care of older people in the European Union. Dublin: European Foundation for the Improvement of Living and Working Conditions, 1995.

7 Rowlands O. Informal carers. London: The Stationery Office, 1998

8 Parker G, Lawton D. Different types of care, different types of carer: evidence from the General Household Survey. London: HMSO, 1994.

9 Qureshi H, Walker A. The caring relationship: elderly people and their families. Basingstoke: Macmillan, 1989.

10 Parker G. With this body: caring and disability in marriage. Buckingham: Open University Press, 1993.

11 Twigg J, Atkin K. Carers perceived: policy and practice in informal care. Buckingham: Open University Press, 1994.

12 Nolan M, Grant G, Keady J. Understanding family care: a multidimensional model of caring and coping. Buckingham: Open University Press, 1996.

13 Aneshensel C, Pearlin L, Mullan J, et al. Profiles of caring: the unexpected career. London: Academic Press, 1995.

14 Tennstedt S, Harrow B, Crawford S. Informal carers vs. formal services: changes in patterns of care over time. J Soc Policy Aging 1996;7;71-91.

15 Todd S, Shearn J. Time and the person: the impact of support services on the lives of parents of adults with intellectual disabilities. J Appl Res Intellect Disabil 1996;9:40-60.

16 Bamford C, Qureshi H, Nicholas E, et al. Outcomes of social care for disabled people and carers. York: Social Policy Research Unit, University of York, 1999.

17 Nocon A, Qureshi H. Outcomes of community care for users and carers. Buckingham: Open University Press, 1996.

18 Department of Health. Caring about carers: a national strategy for carers. London: Department of Health, 1999.

19 Department of Health. Carers and Disabled Children Act 2000: Policy Guidance. London: Department of Health, 2001

20 Department of Health. Quality standards for local carer support services. London: Department of Health, 2000.

21 King's Fund. The carers compass: directions for improving support to carers. London: King's Fund Publishing, 1998.

22 Carers National Association. Primary care projects directory. London: Carers National Association, 1998.

23 Warner L. Seven and a half minutes is not enough: a good practice guide for carers support workers and GP practices. London: The Princess Royal Trust for Carers, 1999

24 Lloyd L. Caring about carers: only half the picture? Critical Social Policy 2000;62:136-50.

25 Taylor MF, ed, with Brice J, Buck N, et al. British household panel survey user manual volume $A$ : introduction, technical report and appendices. Colchester: University of Essex, 1996

26 Buck N, Gershuny J, Rose D, eds. Changing households: the British Household Panel Survey 1990-1992. Colchester: ESRC Research Centre on Micro-Social Change, University of Essex, 1994.

27 Parker G. Counting care: numbers and types of carers. In: Twigg J, ed. Carers: research and practice. London: HMSO, 1992:6-29.

28 Social Services Inspectorate. Carers (Recognition and Services) Act 1995: Practice Guide. London: Department of Health, 1996

29 Corti L, Laurie H, Dex S. Caring and employment. Sheffield: Employment Department, Research Series No. 39, 1994:23.
30 Breslow NE, Day NE. Statistical methods in cancer research: the analysis of case-control studies. Lyon: International Agency for Research on Cancer, 1980:42-53.

31 Plewis I. Analysing change: measurement and explanation using longitudinal data. Chichester: Wiley, 1985:91-2.

32 Gardner M, Altman D. Statistics with confidence. London: British Medical Journal, 1989.

33 Arber S, Ginn J. Gender differences in informal caring. Health Soc Care Community 1995;3:19-31.

34 Hirst M. Trends in informal care in Great Britain during the 1990s. Health Soc Care Community 2001;9:348-57

35 Grundy E. Population review: the population aged 60 and over. Popul Trends 1996;84:14-20.

36 Arber S, Ginn J. Class and caring: a forgotten dimension. Sociology 1992;26:619-34

37 Howe AL, Schofield $\mathrm{H}$, Herrman $\mathrm{H}$. Caregiving: a common or uncommon experience? Soc Sci Med 1997;45:1017-29.

38 Seltzer MM, Li LW. The dynamics of caregiving: transitions during a three year prospective study. Gerontologist 2000;40:165-78.

39 Holzhausen E, Pearlman V. Carers' policies in the UK. Benefits: Journal of Social Security Research, Policy and Practice 2000;28:5-8.

40 Philips J, ed. Working carers. Aldershot: Avebury, 1995

41 Carers National Association. Welfare to work: carers and employment evaluation report. London: Carers National Association, 1999.

42 Henwood M. Ignored and invisible? Carers' experience of the NHS London: Carers National Association, 1998

43 Arksey H. Rationed care: assessing the support needs of informal carers in English social service authorities. J Social Policy 2002;31:81-101.

44 McLaughlin E. Social security and community care: the case of the invalid care allowance. London, HMSO, 1991.

45 Social Services Inspectorate. A matter of chance for carers? London: Department of Health, 1998

46 Heaton J, Arksey H, Sloper P. Carers' experiences of hospital discharge and continuing care in the community. Health Soc Care Community 1999;7:91-9.

47 Hirst M, Baldwin S. Unequal opportunities: growing up disabled. London: HMSO, 1994

48 Schulz R, Newsom J, Fleissner K, et al. The effects of bereavement after family caregiving. Aging Ment Health 1997;1:269-82.

49 Nolan M, Dellasega C. Supporting family carers during long-term care placement for elders. J Adv Nurs 2000;31:759-67.

50 Hancock $\mathbf{R}$, Jarvis $\mathrm{C}$. The long term effects of being a carer. London: HMSO, 1994.

51 McLaughlin E, Ritchie J. Legacies of caring: the experiences and circumstances of ex-carers. Health Soc Care Community 1994;2:241-53.

52 Burchardt T. The dynamics of being disabled. J Soc Policy 2000:29:645-68.

53 Grundy E, Glaser K. Socio-demographic differences in the onset and progression of disability in early old age: a longitudinal study. Age Ageing 2000;29:149-57.

54 Howard M. Paying the price: carers, poverty and social exclusion. London: Child Poverty Action Group, 2001. 